Available online on 15.06.2020 at http://jddtonline.info
Open Access to Pharmaceutical and Medical Research
unrestricted non-commercial use, provided the original work is properly cited

Open $\odot$ Access

Review Article

\title{
Peptic Ulcers and their Complications
}

\section{Akhilesh Kumar*, Dhanesh Kumar, Rajendra Kumar, Jhakeshwar Prasad, Mahendra Kumar, Prachita Joshi, Pratiksha Fulzele}

Department of Pharmacology, Columbia Institute of Pharmacy, Tekari, Raipur, (CG), Pin 493111, India. Affiliated to Chhattisgarh Swami Vivekananda Technology University (CSVTU).

\begin{abstract}
Peptic ulcer disease (PUD) is an uncommon disorder of early life. Peptic ulceration of the stomach or duodenum is usually associated with abnormalities of the gastric mucosa such as gastritis and/or gastropathy. Gastritis and ulcers of the stomach and duodenum can be classified into either primary or secondary depending on their aetiologies. The majority of primary or unexplained peptic ulcers are the result of chronic inflammation caused by Helicobacter pylori infection. However, an increasing number of children with PUD without evidence of H. Pylori infection are now being seen. Rarely PUD is caused by hypersecretory states. Secondary ulceration occurs in response to acute stress from severe systemic illnesses such as sepsis, head injury, burns, and as sequelae to use of certain drugs. The prognosis for recovery from peptic ulcers is good as most patients will respond to treatment.
\end{abstract}

Keywords: Peptic ulcer disease, Complication, Helicobacter pylori, NSAIDs, Management.

Article Info: Received 28 March 2020; Review Completed 19 May 2020; Accepted 25 May 2020; Available online 15 June 2020

\section{Cite this article as:}

Kumar A, Kumar D, Kumar R, Prasad J, Kumar M, Joshi P, Fulzele P, Peptic Ulcers and their Complications, Journal of Drug Delivery and Therapeutics. 2020; 10(3-s):PageNo. http://dx.doi.org/10.22270/jddt.v10i3-s.4082

\section{*Address for Correspondence:}

Akhilesh kumar Sahu, Columbia Institute of Pharmacy, Vill-Tekari, Near Vidhansabha, Raipur, Chhattisgarh, India

\section{INTRODUCTION:}

Peptic ulcer disease (PUD) is a break within the internal lining of the stomach, first part of the small intestine or once in a while the lower esophagus. ${ }^{1,7}$ An ulcer in the stomach is called a gastric ulcer, at the same time as that in the first a part of the intestines is a duodenal ulcer. The most common symptoms of a duodenal ulcer are waking at night time with upper abdominal pain or upper abdominal pain that improves with eating. ${ }^{1}$ With a gastric ulcer the pain might also get worse with eating. ${ }^{8}$ The pain is regularly described as a burningor stupid ache. Other symptoms consist of belching, vomiting, weight loss, or poor appetite. About a third of older human beings have no signs and symptoms. 1 Complications may consist of bleeding, perforation and blockage of the stomach. Bleeding happens in as many as $15 \%$ of people. ${ }^{2}$ Common causes of gastric ulcer include the microorganism Helicobacter pylori and non-steroidal antiinflammatory drugs (NSAIDs). ${ }^{1}$ Other much less not unusual causes include tobacco, smoking, pressure due to extreme illness, Behcet disorder, Zollinger-Ellison syndrome, Crohn disease and liver cirrhosis, amongst others. 1,3 Older people are greater sensitive to the ulcer-causing effect of NSAIDs. 1 The diagnosis is usually suspected because of the offering signs with affirmation by way of both endoscopy or barium swallow. ${ }^{1} \mathrm{H}$. Pylori can be diagnosed by testing of the blood for antibodies, a urea breath take a look at, testing the stool for symptoms of the bacteria, or a biopsy of the stomach. ${ }^{1}$ Other situations that produce similar signs and symptoms consist of stomach cancers, coronary heart disease, and inflammation of the stomach lining or gallbladder inflammation. ${ }^{1}$ Diet does no longer play an important function in either causing or preventing ulcers. ${ }^{9}$ Treatment includes stopping smoking, stopping NSAIDs, preventing alcohol and giving medicinal drugs to lower stomach acid.[1] The medicine used to decrease acid is generally either a proton pump inhibitor (PPI) or an $\mathrm{H}_{2}$ blocker with four weeks of treatment initially recommended. ${ }^{1}$ Ulcers due to $\mathrm{H}$. Pylori are trated with a combination of medications consisting of amoxicillin, clarithromycin and a PPI. 4 Antibiotic resistance is increasing and as a result treatment might not usually be effective. ${ }^{4}$ Bleeding ulcers may be treated with by using endoscopy, with open surgical procedure normally simplest utilized in cases in which it isn't a successful. ${ }^{2}$ Peptic ulcers are found in round $4 \%$ of the populace. ${ }^{1}$ New ulcers were located in around 87.4 million people global all through $2015 .{ }^{5}$ About $10 \%$ of individuals expand a peptic ulcer at some point or another of their existence. 10 They resulted in 267,500 deaths in 2015 down from 327,000 deaths in 1990. 6,11 The first description of a punctured peptic ulcer was in 1670 in Princess Henrietta of England. $2 \mathrm{H}$. Pylori became first recognized as produce peptic ulcers by Robin Warren and Barry Marshall within 
the past due 20 th century, 4 a discovery for which they received the Nobel Prize in 2005. 12

\section{SIGNS AND SYMPTOMS:}

Followings are the signs and symptoms of peptic ulcer:

Abdominal pain, traditionally epigastric strongly associates to mealtimes. In the condition of duodenal ulcers the pain appears around three hours after taking a meal and awakes the patient from rest. Bloating and abdominal completion. Water brash (This is more associated with gastro esophageal reflux disease). Nausea and abundant vomiting. Loss of appetite and weight reduction in gastric ulcer. Weight gain in duodenal ulcer as the pain is relived after meal. Hematemesis (vomiting of blood); this can happen due to bleeding directly from a gastric. Ulcer, or from harm to the esophagus from serious/continuing vomiting. ${ }^{13}$

\section{COMPLICATIONS:}

Gastrointestinalbleeding is the most widely recognized complication. Sudden excess amount of bleeding can be lifethreatening. ${ }^{14}$ It is related with $5 \%$ to $10 \%$ death rate. ${ }^{15}$ Perforation (a hole in the wall of the gastrointestinal tract) following a gastric ulcer regularly prompts disastrous outcomes whenever left untreated. Erosion of the gastrointestinal wall by the ulcer prompts to spillage of the stomach or intestinal substance into the abdominal cavity. Perforation at the anterior surface of the stomach prompts to acute peritonitis, initially chemical and later bacterial peritonitis. The primary sign is often sudden extreme abdominal pain. The death rate in this case is $20 \% .15$ Penetration is a form of perforation in where in the hole prompts and the ulcer proceeds into adjacent organs like as the liver and pancreas. 16 Gastric outlet obstructions is a narrowing of the pyloric canal by scarring and swelling of the gastric antrum and duodenum becau se of peptic ulcers. The person often presents with serious vomiting. 15 Cancer is included in the differential diagnosis (explained bybiopsy), Helicobacter pylorias the etiological factor chance it 3 to 6 times more likely to develop stomach cancer from the ulcer. 16

\section{CAUSES OF PEPTIC ULCERATION:}

\section{Infection: Helicobacter pylori}

Drugs: Non-steroidal anti-inflammatory drugs (including aspirin), Steroids, Bisphosphonates, Immunosuppressant's, Cocaine.

Stress: Psychological, Physical e burns (Curling's ulcer), Head injury (Cushing's ulcer. Tobacco smoking, Alcohol intake, Zollingere Ellison syndrome (Gastrinomas), Agerelated decline in prostaglandin levels.

\section{EPIDEMIOLOGY:}

Epidemiological shows that PUD stays a moderately common condition worldwide, with yearly rate running from $0.10 \%$ to $0.19 \%$ for physician-diagnosed PUD and from $0.03 \%$ to $0.17 \%$ for PUD diagnosed during hospitalization ${ }^{17}$. The 1-year predominance of physician diagnosed PUD was $0.12-1.5 \%$, and the 1-year prevalence of PUD diagnosed during hospitalizations was $0.10-0.19 \%{ }^{17}$. The data show that the incidence of PUD has decreased over recent decades in many nations, in all likelihood because of the abatement in $H$. pylori infection, especially in Western populations. However, it is possible that the circumstance might be distinctive in Asian nations; an ongoing study in Korea revealed that the prevalence of $H$. pylori infection in relationship with GU was expanding with time, whereas $H$. pylori infection in DU was decreasing. 18 The most dependable investigation of physician-diagnosed predominance was from Sweden, reporting cross-sectional data illustrative of the general population 19; the examination in this manner included both symptomatic and asymptomatic PUD. The overall predominance of PUD saw in this study was $4.1 \% ; 19.5 \%$ of all PUD cases recognized were asymptomatic. Comparing this prevalence with the lower rates obtained from other investigation of physician diagnosed PUD in primary care propose that a proportion of people with PUD remain undiagnosed. In people with asymptomatic PUD, extreme complications, for example gastrointestinal haemorrhage, may be the first indication of the disease. Haemorrhage is related with mortality approaching $10 \%$ and high recurrence 20 . Literature shows that the reported incidence and prevalence of PUD have decreased over time in recent decades. However, fleeting trends in the rate of hospitalizations for complications of PUD changed, remaining unchanged or expanding in ongoing decades in two studies in Finland and the Netherlands 21-22, but declining over time in one study in Scotland 23. The lifetime risk for peptic ulcer in infected individuals ranges from 3\% in the United States to 25\% in Japan 24.

\section{ETIOLOGY:}

Till the last decade it has been evaluated that $95 \%$ of duodenal ulcer and $70 \%$ of gastric ulcer is credited because of $H$. pylori 25 . About $14 \%-25 \%$ of gastric and duodenal ulcers are seen as related with NSAID use 26 . Interaction data and randomized trial with NSAIDs and $H$. pylori annihilation therapy uncovered that the ulcer-inducing effects of both hazard factors are cumulative 27,28 . However, their potential interaction in the producing of ulcer disease remains unidentified. Eradication of $\mathrm{H}$ pylori didn't reduces the rate of ulcer relapse in existing long term NSAID users ${ }^{29}$. PUDs posse a multifactorial disease pathway significantly represented by acid disbalance and low mucosal defense prompting inflammation. This is represented by hyper section of hydrochloric acid and pepsin. This causes an imbalance between gastric luminal element and degradation in the protective capacity of the gastric mucosal barrier for example mucus, secretion of bicarbonate, mucosal blood flow, and epithelial cell defense. On attack of acid and pepsin through a weakened area of the mucosal barrier prompts the release of histamine. Histamine stimulates parietal cells to secrete more acid. With the continuation of this endless loop resulting in disintegration to form the ulcer.

\section{Role of H. Pylori infection:}

H.pylori prompted ulcer development is impacted by a variety of host and bacterial factors. Ulcers mostly occur at sites of most serious mucosal inflammation ${ }^{30}$. Decreased acid output, usually is the gastric transitional zone between corpus and antrum, offer ascent to gastric ulcer disease. If acid production is normal to high, the most serious inflammation normally is found in the distal stomach and proximal duodenum, offering ascend to juxta-pyloric and duodenal ulcer disease. Anperson's definitive clinical outcome is dependent on the cytokine response and on the gastric acid secretion 30-31. An increase in stimulated acid production predisposes to duodenal ulceration and decreased acid formation predisposes to corpus gastritis or pangastritis which in turn predisposes to gastric ulceration, atrophic gastritis, and gastric carcinoma 30-31. The intragastric distribution of gastritis is thought to be dependent on host genetic factors, bacterial harmfulness factors and environmental factors including age at beginning of infection 31 . 


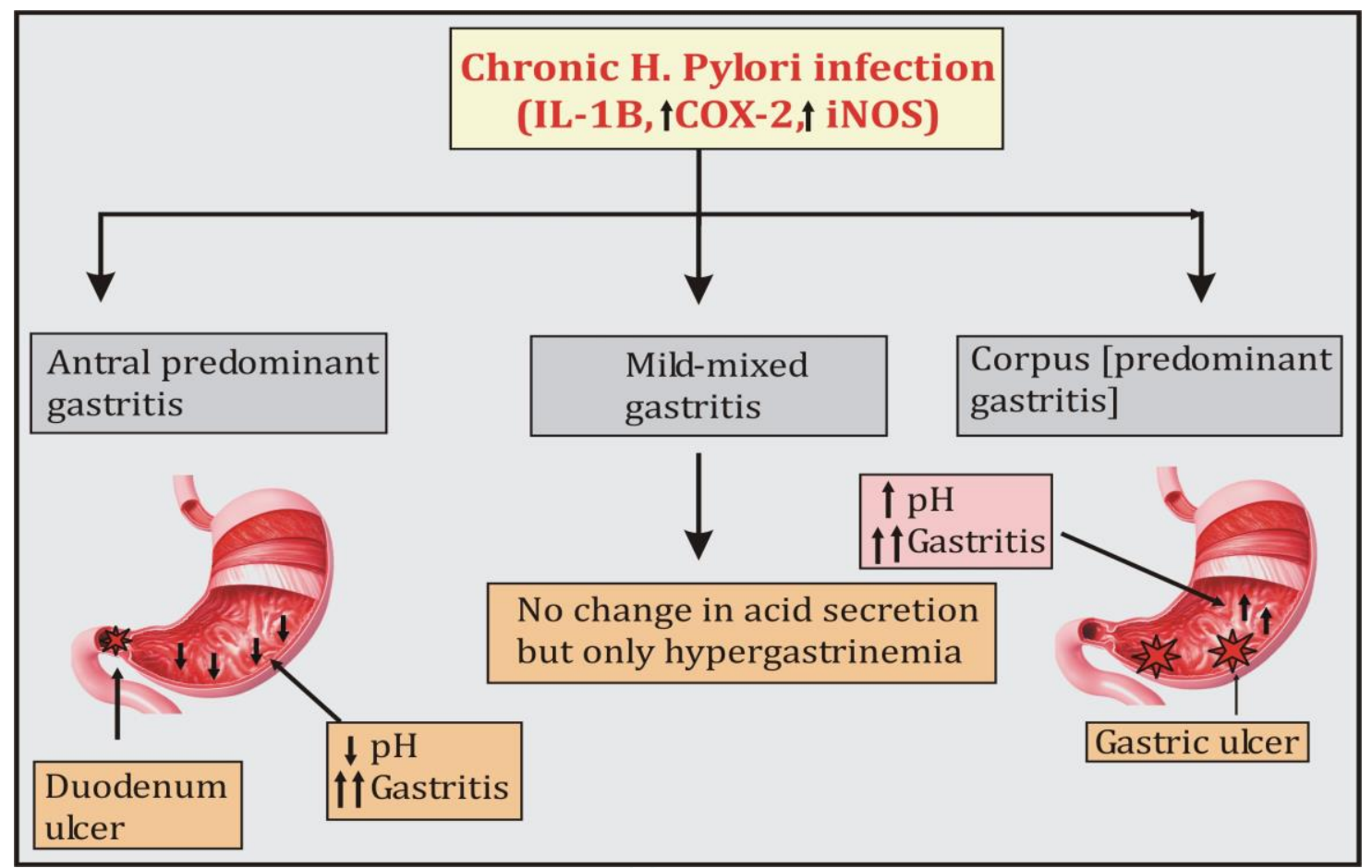

Figure 1: Depicting colonization of $H$. pylori in different regions of the stomach leading to various gastroduodenal diseases.

Duodenal ulcers are related with H. pylori-induced antrumpredominant gastritis, diminished somatostatin levels and enlarged gastrin and acid secretion 32. Development of gastric metaplasia in the duodenum further permits bacterial colonization, in this manner prompting to duodenitis and epithelial damage. Gastric ulcers are associated with corpus gastritis, which is accepted to damage the epithelium 32. Eradication of the infection recuperates peptic ulcer disease, restablidhes ordinary acid secretion and prevents ulcer relapse 33 . Host response plays a critical role in $H$. pylori induced ulceration. The humoral immune system has only marginal pertinece for defensive immunity in $H$. pylori infection. $H$. pylori induce a Th1polarized response that unfortunately doesn't result in clearance of the infection. H. pylori is thought to constrol the host immune response and inflammation 34. The key activator of the innate immune response is presumably intracellular peptidoglycan 34. H. pylori is able for the inhibiting phagocytosis by macrophages by an as-yet unknown mechanism. IL-10-producing T cells appearto be essential in the control of inflammation and they enable the bacteria to persevere in gastric mucosa 34 . Several cytokine genes have stable polymorphisms which are known to influence the level of cytokine production in response to $H$. pylori infection 35 . The best known of these is interleukin-1 $\beta$, a potent proinflammatory cytokine and the most potent known inhibitor of acid secretion 34. These cytokine polymorphisms may contribute to the danger of gastric adenocarcinoma, but their contribution to the danger of peptic ulceration is conflicting ${ }^{36-37}$.

\section{Role of NSAIDs:}

Severe ulcer complications and gastrointestinal damages have been associated with NSAIDs, since last two decades. The risk of these complications have been found to increase with geriatric population [38], previous history of peptic ulceration, and presumably the initial three months of NSAID treatment.. Endoscopic examination reported more gastric than duodenal ulcers related with NSAID use, however, patients shows the result with gastrointestinal bleeding on NSAIDs may have a comparative frequency of gastric and duodenal ulceration. NSAIDs will in general impact the Cyclo-Oxygenase (COX) pathways which lead to generate of prostanoids (prostaglandins, prostacycline, and thromboxane). This effect the mucosal protection by diminishing the effectiveness of the mucus-bicarbonate obstruction; gastric acid, and possibly also pepsin, plausibly causing damage. As most NSAIDs are also weak acids may also be a contributory factor responsible ulceration 39 .

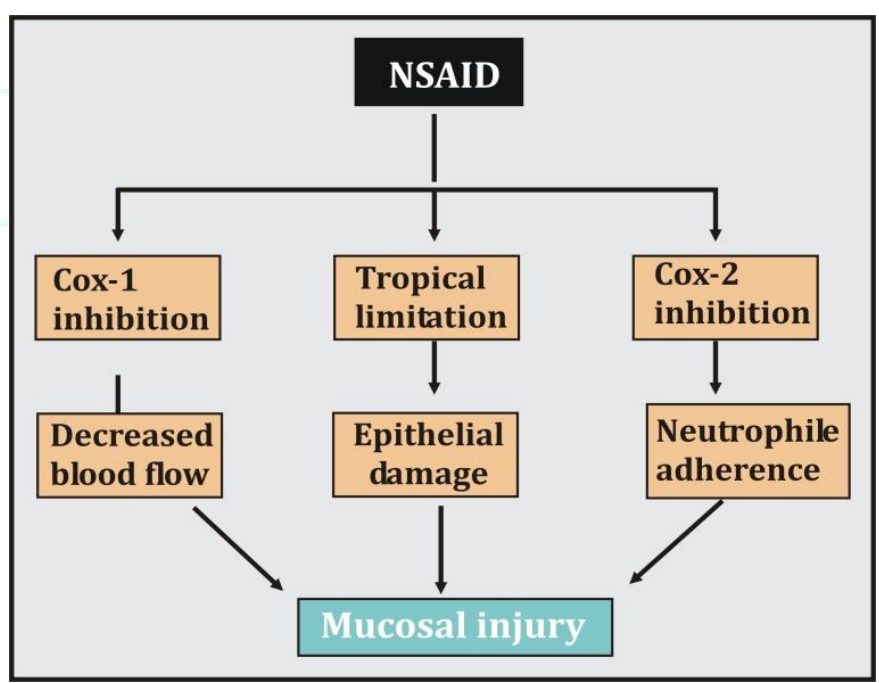

Figure 2: Pathogenesis of NSAIDs induced GI injury.

\section{Stress:}

Stress due to serious health problems for example, those requiring treatment in an emergency care unit is well described as a reason for peptic ulcers, which are also called as stress_ulcers. While chronic life stress was once accepted to be the main cause of ulcers, this is no longer the case. It is, however, even now occasionally accepted to play a role. This may be due to the well documented impact of stress on 
gastric physiology, expanding the risk in those with other causes for example H. pylori or NSAID use.

\section{Diet:}

Dietary factors, like as, spice consumption, were hypothesized to cause ulcers until late in the 20th century, however have been demonstrated to be of relatively minor importance. Caffeine and coffee, also commonly thought to cause or exacerbate ulcers, seem to have little effect. Similarly, while studies have discovered that alcohol consumption expands risk when associated with $H$. pylori infection, it does not appear to independently increase risk. Even when coupled with $H$. pylori infection, the increase is modest in comparison with the essential primary risk factor.

\section{Other:}

Other reasons for peptic ulcer disease includes: gastric ischemia, drugs, metabolic disturbances, cytomegalovirus (CMV), upper abdominal radiotherapy, Crohn'sdisease, and vasculitis. Gastrinomas (Zollinger= Ellisonsyndrome), rare gastrin-secreting tumors, also cause multiple and difficult-to-heal ulcers. is still unclear if smoking increases the danger of getting peptic ulcers.

\section{DIAGNOSIS OF PEPTIC ULCER DISEASE:}

Peptic ulceration is a diagnosis usually confirmed by flexible upper GI endoscopy. An ulcer is defined as a mucosal break with a diameter greater than $5 \mathrm{~mm}$. Ulcers may be single or multiple and most commonly affect the lesser curve of the stomach and the first part of the duodenum. Gastric ulcers should be biopsied in every instance to exclude malignancy. All patients with a gastric ulcer should undergo a repeat endoscopy in 6 to 8 weeks following treatment to ensure ulcer healing, and further biopsies should be taken if there is any evidence of ongoing ulceration. This should be repeated until the ulcer has fully healed. During endoscopy for suspected peptic ulceration it is also possible to test for $\mathrm{H}$. pylori by biopsying the gastric mucosa for histological identification, microbiological culture or rapid urease test.

The rapid urease test (CLO test_) is widely available and the most commonly used method of detecting H. pylori during endoscopy. It has the advantage of being quick, cost effective, with a high sensitivity (97\%) and specificity (100\%) when multiple biopsies are taken. If $\mathrm{H}$. pylori infection is present the organism will produce the enzyme urease, which catalyses the conversion of urea (within the gel in which it is placed), resulting in the production of alkaline ammonium ions that will increase the $\mathrm{pH}$ and result in change in the colour of the gel from yellow to red. Histological identification and microbiological culture are costly and labour intensive and are therefore used less commonly. Less invasive diagnostic tests for $\mathrm{H}$. pylori are also available for those patients who do not proceed to endoscopy. These include a urea breath test (sensitivity $95 \%$ and specificity $100 \%$ ) that relies on the ability of H. pylori to metabolize orally administered carbon radio-labelled urea to carbon dioxide, which is exhaled by the patient and subsequently detected on the breath. Recent studies evaluating the increasingly common $\mathrm{H}$. pylori stool antigen test as an alternative non-invasive test have demonstrated sensitivity and specificity of approximately 95\%.[40] Serology for H. Pylori antigen is generally not recommended as it has potential to give false positive results in those with past but no current infection. False positive results can also occur in both the biopsy based urease and urea breath tests among patients receiving current acid suppression medication.

\section{MANAGEMENT OF UNCOMPLICATED PEPTIC ULCER DISEASE:}

The development of acid reduction pharmacological therapies and eradication strategies for $\mathrm{H}$. pylori has revolutionized modern peptic ulcer management. The vast majority of patients with uncomplicated peptic ulcer disease can be treated and cured with medical treatment. The mainstay of management involves acid suppression, eradication of $\mathrm{H}$. pylori (if present), and modification of etiological factors. With the introduction of H2-receptor antagonists (H2-blockers) came the ability to heal ulcers and control symptoms without the need for sub-optimal surgical procedures. These drugs, which include ranitidine and cimetidine, block the histamine receptor on gastric parietal cells and reduce the secretion of gastric acid.

Subsequently, proton pump inhibitors (PPI) have now largely superseded the use of H2-blockers. PPIs, for example, omeprazole and lansoprazole, act by blocking the final process in hydrogen ion secretion by the mucosal parietal cells through H-K-ATPase inhibition. Studies have shown improved ulcer healing rates with the use of PPIs compared with $\mathrm{H} 2$ blockers, most likely due to the ability of these agents to completely suppress acid production and allow for no external stimulation from gastrin or vagal activity. PPIs are generally well tolerated but there are some concerns regarding long-term use with regards to the theoretical risk of developing vitamin B12 and iron deficiency, the proven potential for increased enteric infections such as Clostridium difficile, and potential increased risk of gastric cancer development through PPI-induced mucosal atrophy. More recently, some studies have suggested an association between long-term PPI use and increased risk of hip fractures, although this association has been refuted in other studies. Consideration should be given to supplemental intake of calcium and vitamin D in patients at increased risk of osteoporosis on long-term PPI treatment. In addition, PPI agents may cause hypomagnesaemia with prolonged use. It is therefore recommended that, while these risks are small and the benefits of PPI outweigh the risks in the majority of patients, the lowest efficacious dose should be administered and stopped if no longer clinically indicated. Proton pump inhibitors are equally effective in the treatment of both $\mathrm{H}$. pylori positive and negative peptic ulceration.

In those with $H$. pylori positive peptic ulceration, identification and eradication leads to resolution of gastric and duodenal ulcers in the majority of cases. Furthermore, in patients with unexplained persistent peptic ulceration initially found to be H. pylori negative, repeat tests should be used to confirm H. Pylori negativity. Eradication regimes vary by region due to local drug resistance patterns, but should be effective in approximately $80 \%$ of cases (Table 1 ). Effectiveness of eradication should be assessed by monitoring of symptoms. If symptoms persist then eradication should be confirmed with further diagnostic testing. Truly idiopathic ulcers are rare and, therefore, every effort should be made to identify potential etiological factors. In addition to the medical management described above, consideration should be given to addressing lifestyle measures that may contribute to the development of peptic ulceration, such as smoking cessation, reducing alcohol intake, and stopping NSAIDs (Table 2). 
Table: 1 Examples of Helicobacter pylori eradication regimes

\begin{tabular}{|c|c|c|c|}
\hline \multirow[t]{2}{*}{ Acid suppression } & \multicolumn{3}{|c|}{ Antibacterial medication } \\
\hline & Amoxicillin & Clarithromycin & Metronidazole \\
\hline Twice daily dose of any PPI including & $1 \mathrm{~g}$ twice daily & 500 mg twice daily & - \\
\hline Esomeprazole, Lansoprazole, Omeprazole, & - & $250 \mathrm{mg}$ twice daily & 400 mg twice daily \\
\hline Pantoprazole and Rabeprazole & $1 \mathrm{~g}$ twice daily* & - & 400 mg twice daily* \\
\hline \multicolumn{4}{|c|}{$\begin{array}{l}\text { Seven day course for approximately } 85 \% \text { eradication. If penicillin allergic or recent use of metronidazole or a } \\
\text { macrolide then an alternative regime should be used. *Formuse with omeprazole, amoxicillin dose } 500 \mathrm{mg} \text { three } \\
\text { times daily and metronidazole } 400 \mathrm{mg} \text { three times daily. (from British National Formulary 67) }\end{array}$} \\
\hline
\end{tabular}

Table 2: Factors associated with the development and progression of peptic ulcer disease

\begin{tabular}{ll}
\hline Infective & Helicobacter pylori infection, Cytomegalovirus, Herpes simplex virus \\
\hline Drugs & Non-steroidal anti-inflammatory drugs, Acetylsalicylic acid (Aspirin), Corticosteroids \\
\hline Increased acid production & Zollinger-Ellison syndrome (gastrinoma) \\
\hline Post surgical & Anastomotic marginal following gastric surgery \\
Malignancy & Adenocarcinoma, Lymphoma \\
Autoimmune & Crohn's disease \\
Stress & $\begin{array}{l}\text { Secondary to burns (Curling's ulcer), head injury (Cushing's ulcer), trauma, sepsis and } \\
\text { multiple organ failure }\end{array}$ \\
Life style & Alcohol intake, Smoking \\
\hline
\end{tabular}

\section{MANAGEMENT OF ACUTE BLEEDING PEPTIC ULCER DISEASE:}

Major complications of peptic ulcer disease include bleeding, perforation and gastric outflow obstruction. Of these, bleeding is the most common complication and is responsible for 50,00-70,000 emergency hospital admissions per year in the UK.[41] Approximately 5 to $10 \%$ of patients admitted with a bleeding peptic ulcer will die as a consequence of the bleed. Riskfactors for mortality include old age, associated comorbidity, NSAID use and hemodynamic instability on presentation. [41]

\section{REFERENCES:}

1. Najm WI. "Peptic ulcer disease". Primary Care September 2011; 38 (3):383-94, vii. doi:10.1016/j.pop.2011.05.001.

2. Milosavljevic T, Kostić-Milosavljević M, Jovanović I, Krstić M. "Complications of peptic ulcer disease". Digestive Diseases 2011; 29 (5):491-3. doi:10.1159/000331517. .

3. Steinberg KP. "Stress-related mucosal disease in the critically ill patient: risk factors and strategies to prevent stress-related bleeding in the intensive care unit". Critical Care Medicine 2002; 30 (6 Suppl): S362-4. doi:10.1097/00003246200206001-00005.

4. Wang AY, Peura DA. "The prevalence and incidence of Helicobacter pylori-associated peptic ulcer disease and upper gastrointestinal bleeding throughout the world". Gastrointestinal Endoscopy Clinics of North America 2011; 21 (4):613-35. doi:10.1016/j.giec.2011.07.011.

5. GBD 2015 Disease and Injury Incidence and Prevalence Collaborators. "Global, regional, and national incidence, prevalence, and years lived with disability for 310 diseases and injuries, 1990-2015: a systematic analysis for the Global Burden of Disease Study 2015". Lancet 2016; 388 (10053):1545-1602. doi:10.1016/S01406736(16)31678-6.

6. Wang, Haidong; Naghavi, Mohsen; Allen, Christine; Barber, Ryan M.; Bhutta, Zulfiqar A.; Carter, Austin; Casey, Daniel C.
Charlson, Fiona J.; Chen, Alan Zian; Coates, Matthew M.; Coggeshall, Megan; Dandona, Lalit; Dicker, Daniel J.; et al. (October 2016). "Global, regional, and national life expectancy, all-cause mortality, and cause-specific mortality for 249 causes of death, 1980-2015: a systematic analysis for the Global Burden of Disease Study

2015". Lancet. 388 (10053):1459-1544. doi:10.1016/s01406736(16)31012-1.

7. "Definition and Facts for Peptic Ulcer Disease". National Institute of Diabetes and Digestive and Kidney Diseases. Archived from the original on 2 April 2015. Retrieved 28 February 2015.

8. Rao, S. Devaji. Clinical Manual of Surgery. Elsevier Health Sciences. 2014 p. 526. ISBN 9788131238714.

9. "Eating, Diet, and Nutrition for Peptic Ulcer Disease". National Institute of Diabetes and Digestive and Kidney

Diseases. Archived from the original on 20 March 2015. Retrieved 28 February 2015.

10. Snowden FM. "Emerging and reemerging diseases: a historical perspective". Immunological Reviews. 2008; 225 (1):926. doi:10.1111/j.1600-065X.2008.00677.x.

11. GBD 2013 Mortality Causes of Death Collaborators (January 2015). "Global, regional, and national age-sex specific all-cause and cause-specific mortality for 240 causes of death, 19902013: a systematic analysis for the Global Burden of Disease Study 2013". Lancet. 385 (9963):117-71. doi:10.1016/S01406736(14)61682-2.

12. "The Nobel Prize in Physiology or Medicine 2005". nobelprize.org. Nobel Media AB. Archived from the original on 12 May 2015. Retrieved 3 June 2015.

13. Bhat S. SRB's Manual of Surgery. 2013; p. 364. ISBN 9789350259443.

14. Cullen DJ, Hawkey GM, Greenwood DC, Humphreys H, Shepherd V, Logan RF, Hawkey CJ. "Peptic ulcer bleeding in the elderly: relative roles of Helicobacter pylori and non-steroidal antiinflammatory drugs". Gut. 1997; 41(4):459 62. doi:10.1136/gut.41.4.459. 
15. Lanas A, Chan FK. "Peptic ulcer disease". Lancet.2017; 390(10094):613-624. doi:10.1016/S0140-6736(16)324047.

16. "Peptic Ulcer". Home Health Handbook for Patients \& Caregivers. Merck Manuals. October 2006. Archived from the original on 28 December 2011.

17. Sung JJ, Kuipers EJ, El-Serag HB. Systematic review: the global incidence and prevalence of peptic ulcer disease. Aliment PharmacolTher. 2009; 29: 938-946.

18. Jang HJ, Choi MH, Shin WG, Kim KH, Chung YW. Has peptic ulcer disease changed during the past ten years in Korea? A prospective multi-center study. Dig Dis Sci. 2008; 53:15271531.

19. Aro P, Storskrubb T, Ronkainen J, Bolling-Sternevald E, Engstrand L, et al. Peptic ulcer disease in a general adult population: the Kalixanda study: a random population-based study. Am J Epidemiol, 2006; 163:1025-1034.

20. Christensen S, Riis A, Nørgaard M, Sørensen HT, Thomsen RW. Short-term mortality after perforated or bleeding peptic ulcer among elderly patients: a population-based cohort study. BMC Geriatr. 2007; 7:8.

21. Paimela H, Paimela L, Myllykangas-Luosujärvi R, Kivilaakso E. Current features of peptic ulcer disease in Finland: incidence of surgery, hospital admissions and mortality for the disease during the past twenty-five years.Scand J Gastroenterol. 2002; 37:399-403.

22. Post PN, Kuipers EJ, Meijer GA. Declining incidence of peptic ulcer but not of its complications: a nation-wide study in The Netherlands. Aliment PharmacolTher. 2006; 23:1587-1593.

23. Kang JY, Elders A, Majeed A, Maxwell JD, Bardhan KD. Recent trends in hospital admissions and mortality rates for peptic ulcer in Scotland 1982-2002. Aliment PharmacolTher. 2006; 24:65-79.

24. Suerbaum S, Michetti P. Helicobacter pylori infection. N Engl J Med. 2002; 347:1175-1186.

25. Rothenbacher D, Brenner H. Burden of Helicobacter pylori and H. pylori-related diseases in developed countries: recent developments and future implications. Microbes Infect. 2003; 5:693-703.

26. Hudson N, Hawkey CJ. Non-steroidal anti-inflammatory drug associated upper gastrointestinal ulceration and complications. Eur J GastroenterolHepatol. 1993; 5:412-419.

27. Huang JQ, Sridhar S, Hunt RH. Role of Helicobacter pylori infection and non-steroidal anti-inflammatory drugs in pepticulcer disease: a meta-analysis. Lancet. 2002; 359:14-22.

28. Chan FK, To KF, Wu JC, Yung MY, Leung WK. Eradication of Helicobacter pylori and risk of peptic ulcers in patients starting long-term treatment with non-steroidal antiinflammatory drugs: a rando mised trial. Lancet. 2002; 359:913.

29. Hawkey CJ, Tulassay Z, Szczepanski L, van Rensburg CJ, Filipowicz-Sosnowska A. Randomised controlled trial of Helicobacter pylori eradication in patients on non-steroidal anti-inflammatory drugs: HELP NSAIDs study. Helicobacter Eradication for Lesion Prevention.Lancet. 1998; 352: 10161021.

30. Lochhead P, El-Omar EM. Helicobacter pylori infection and gastric cancer. Best Pract Res ClinGastroenterol. 2007; 21:281297.

31. Robinson K, Argent RH, Atherton JC. The inflammatory and immune response to Helicobacter pylori infection. Best Pract Res ClinGastroenterol. 2007; 21:237-259.

32. Blaser MJ, Atherton JC. Helicobacter pylori persistence: biology and disease. J Clin Invest. 2004; 113:321-333.

33. Ford AC, Delaney BC, Forman D, Moayyedi P. Eradication therapy in Helicobacter pylori positive peptic ulcer disease: systematic review and economic analysis. Am J Gastroenterol. 2004; 99:1833-1855.

34. Kusters JG, van Vliet AH, Kuipers EJ. Pathogenesis of Helicobacter pylori infection. ClinMicrobiol Rev. 2006; 19:449490.

35. El-Omar EM. Role of host genes in sporadic gastric cancer. Best Pract Res ClinGastroenterol. 2006; 20: 675-686.

36. Chakravorty M, Ghosh A, Choudhury A, Santra A, Hembrum J, et al. Interaction between IL-1ß gene promoter polymorphisms in determining susceptibility to Helicobacter pylori associated duodenal ulcer. Hum Mutat. 2006; 27:411-419.

37. Robinson K, Argent RH, Atherton JC. The inflammatory and immune response to Helicobacter pylori infection. Best Pract Res ClinGastroenterol. 2007; 21:237-259.

38. Allison MC, Howatson AG, Torrance CJ, Lee FD, Russell RI. Gastrointestinal damage associated with the use of nonsteroidal antiinflammatory drugs. N Engl J Med. 1992; 327:749-754.

39. Russell RI. Non-steroidal anti-inflammatory drugs and gastrointestinal damage-problems and solutions. Postgrad Med J. 2001; 77:82-88.

40. McNulty CA, Lehours P, Megraud F. Diagnosis of Helicobacter pylori infection. Helicobacter 2011; 16(suppl 1):10e8.

41. NICE. Acute upper gastrointestinal bleeding: management. London: National Institute for Health and Care Excellence, 2012. 